\title{
Commercialization Plan \\ for Argonne's Lubricious Coatings
}

\section{DISCLAIMER}

This report was prepared as an account of work sponsored by an agency of the Unitud States Government. Neit'.ar the United States Government nor any agency thereof, nor any of their employees, makes any warranty, express or implied, or assi mes any legal liability or responsibility for the accuracy, completeness, or usefulness of any intsrmation, apparatus, product, oi process disclosed, or represents that its use would not infringe pr: utely owned rights. Refer ence herein to any specific commercial product, process, or service by trade name, trademark, manufacturer, or otherwise does not necessarily constitute or imply its endorsement, recommendation, or favoring by the United States Government or any agency thereof. The views and opinions of authors expressed herein do not necessarily state or reflect those of the United States Government or any agency thereof.

Prepared by:

The Industrial Technology Institute

Ann Arbor, Michigan

\section{March 1991}


14 March 1991

\author{
Commercialization Plan \\ for Argonne's Lubricious Coatings
}

This report summarizes an interview conducted with Dr. David S. Grummon, a specialist in ion beam assisted deposition (IBAD) and coatings at Michigan State University, to define the concept and components of an ion beam assisted deposition (IBAD) system; summarizes findings of a literature search cunducted to identify prior and current efforts in developing lubricious coatings; and reports on the market potential for Argonne's IBAD lubricious coating process.

\title{
Concept and Components of an IBAD System
}

The principle concept of IBAD is to use accelerated ions to attach evaporated ions to a substrate to form a thin coating. IBAD generally uses two ion sources: a deposition source and an ion assist beam. The accelerated ions have energies in the moderate $100-1000 \mathrm{eV}$ range. The accelerated ions hit the evaporated ions akin to billiard balls hitting and attach the evaporated ions onto a target surface. Since the accelerated ions have only moderate energy, upon hitting the evaporated ions or coating source they "tap" the evaporated ions onto the target surface. IBAD has proven to be an effective process for applying coatings. The following diagram (Source: Logos, Argonne National Laboratory (ANL), Vol 8 \#2, 1990) illustrates the basic IBAD concept.

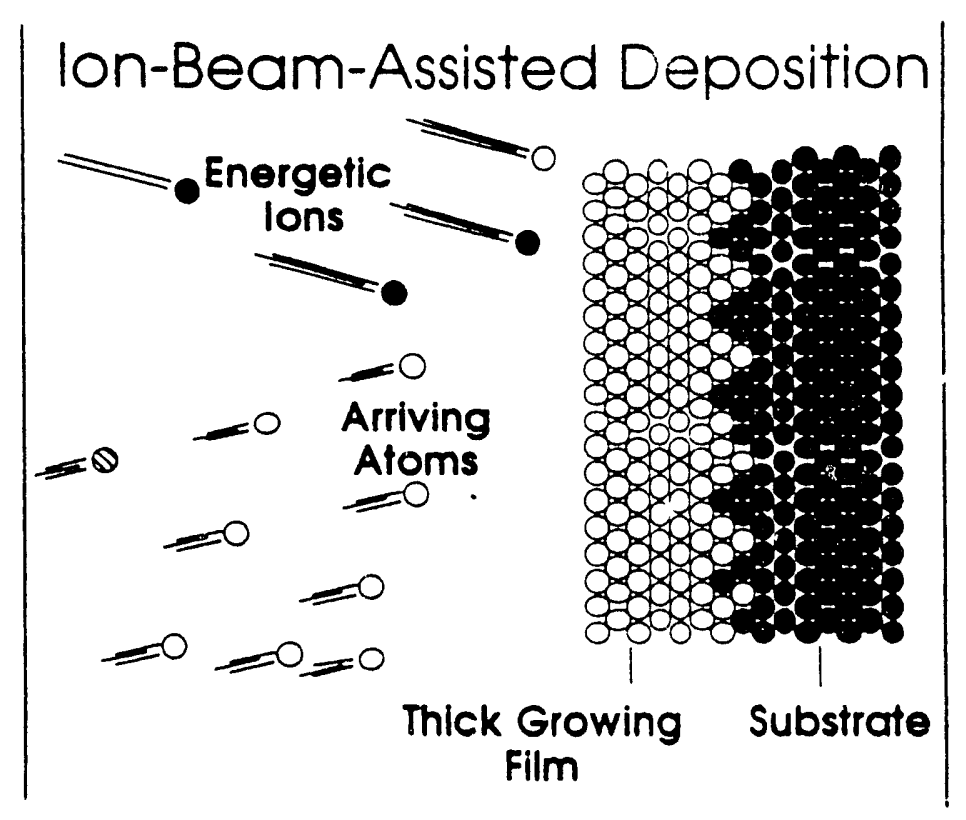


Prior ion technologies include sputtering, ion plating, and ion implantation. Ion beam mixing is contemporaneous with and closely related to IBAD. These technologies differ in their ion energy source which effects the way in which the evaporated ions are attached to a substrate. For example, sputtering relies on neutral atoms ejected from a sputtering source by the impingement of ions energized by high voltage D.C. or radio frequency power, typically around $1 \mathrm{eV}$; therefore, according to ANL researchers, the resulting coating is relatively weak and porous. In contrast, ion implantation uses ionized atoms to modify the surface. The ions have enough energy to penetrate the substrate to a substantial depth. Ion implantation energizes icns in the 30,000 to over one million $\mathrm{eV}$ range, so evaporated ions not only adhere to the surface but are actually pushed into the suo surface of the target substrate. Ion implantation is not a coating process but a surface modification process. Substrates modified with the ion implantation technique are durable and long lasting. The primary disadvantage of the ion implantation technique is high cost. 'The following diagrams (Source: Logos, ANL Vol 8 \#2, 1980) illustrate the fundamental difference between IBAD and ion beam mixing and implantation concepts.

lon-Beam Mixing Ion-Beam Mixed Zone $\rightarrow-1$

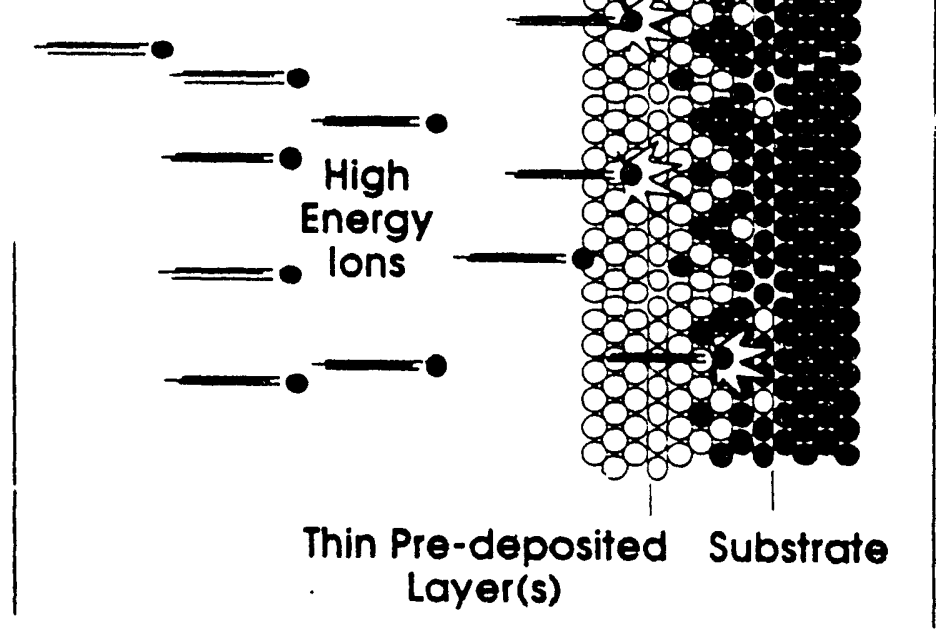

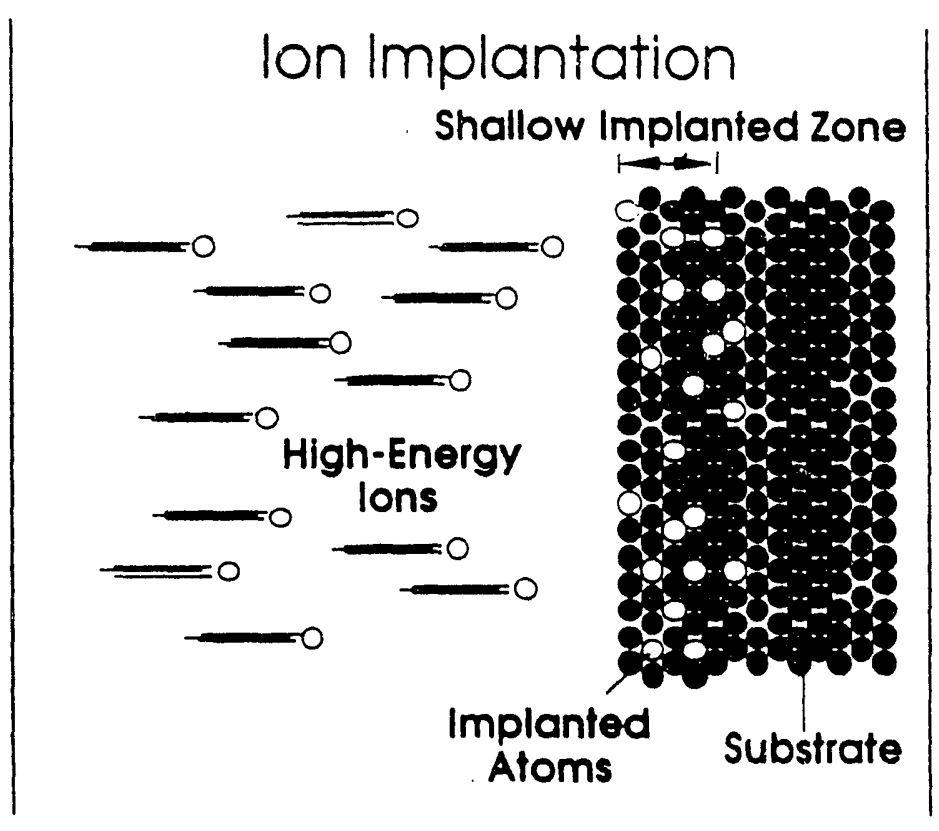


A continuum baseu on ion energy source is attached at the end of this report to show the IBAD process in relation to other ion technologies.

The primary advantage of IBAD is lower cost when compared to ion implantation. In addition, a valuable feature of IBAD is its ability to coat a part without changing its dimensional tolerances.

\section{Components of an IBAD System}

Components of an IBAD system are a coating source, an energy ion source, and a vacuum chamber. The coating source is a device that evaporates ions. The type of material or materials determines what kind of coating source is best. Coating sources include an electron beam hearth, thermal evaporation source, magnetron sputtering source, ion sputtering, and a knudsen cell (effusion source).

The energy ion source is a device that accelerates the ions. Energy ion sources include ion and Kaufman guns, and other linear accelerators. Ion guns for IBAD are readily available and have a cost range of $\$ 14,000$ to $\$ 50,000$. Current capacity is important and determines the time a given process will take to complete. Gridless energy sources have an energy range 42-140 eV. Gridded guns can also be used for IBAD and are rated on beam diameters which range from 1 centimeter to 38 centimeters; however, a gridded device cannot extract a lot of current from the ion source at low energies. Ion energies of Kaufman guns range from from $100-2000 \mathrm{eV}$. Another kind of energy source used in an $\mathrm{IBAD}$ process is a linear accelerator. Linear accelerators can achieve energies up to $400,000 \mathrm{eV}$ and are capable of ion implantation. High voltage linear accelerators cost millions of dollars and are only used in research and highly specialized applications.

Ion energy sources are typically line of sight instruments; therefore, careful positioning of the ion energy source or sources or rotating the target surface is required. Some new techniques, such as pulsed ion plating can overcome line of sight limitations to some degree.

The vacuum chamber is made of stainless steel or aluminum and provides various mounting options for the coating source, ion energy source, and target substrate. Most have a variable pressure control. The IBAD process requires that the chamber, coating source, and ion energy source be free of any contaminant so cleaning and handling 
procedures must be followed. The most critical feature of the vacuum chamber is size to accommodate target substrates. Spire Corporation, a leading ion technology provider, is currently developing a $20 "$ by $20 "$ chamber for commercial applications.

\section{IBAD Techniques}

Numerous techniques can be employed during the IBAD process to achieve coating results, such as compound coatings and adhesion of coatings to certain substrates. Techniques include use of multiple coating sources, multiple ion energy sources, use of inert and reactive gases in the ion energy source, substrate heating or cooling, and using the assist beam only in the early stages of deposition to clean the substrate and to achieve a little ion beam mixing of the first few atom layers of the deposit. Technique depends on coating material and substrate properties.

\section{Existing Ion Technology Providers}

The following sample of firms, which were obtained from the Thomas Registry, provide ion implantation, plating, evaporation, and sputter deposition services and systems. According to Grummon and articles published by the Spire Corporation, these firms will likely be the commercial providers of IBAD services and systems. Barriers to widespread use of pre-IBAD technology have been documented by ion technology providers. According to Spire, barriers are general unfamiliarity with the processes, scarcity of suitable equipment, wide diversity of potential applications, other emerging competitive surface modification techniques, and industrial conservatism. Overlapping concerns were mentioned by Ralph Alexander, a Michigan based ion technology provider who was recommended to ITI by Grummon, and include market barriers, such as costs, industrial conservatism and production priorities in manufacturing; and technical barriers, such as size of available implanters, line of sight limitations, and shallow penetration depth. However, according to Spire, IBAD may not experience these barriers because it is an improvement over existing technologies (evaporation and sputtering).

Established applications which use implantation technologies are precision tooling, medical prothesis, and semiconductors while developing applications are in aerospace and optical coating. In these applications the primary use of the surface modification is to provide superior wear resistance. 
Providers of ion technologies services include:

1. Ralph Alexander Ion Surface Technology, 1030-F North Crooks Road Clawson, MI 48017 (313) 280-1660

2. Arias Research Associates Whittier, CA (currently performing research comparing ion assisted deposition and ion plating techniques. Measurement includes photothermal deflection and angular, scattering which seem critical for optical coatings.)

3. The Implant Center, San Jose, CA

4. Ion Implantation Corp., Santa Clara, CA

5. Ion Implantation Services, Sunnyvale, CA

6. MCE Semiconductor, West Palm Beach, FL

7. Spire Corp., Bedford, MA

8. Implant Sciences Corp., Danvers, MA (systems also)

9. General Diode Corp., Framingham, MA

10. Universal Energy Systems, Dayton, $\mathrm{OH}$

11. BeamAlloy Corp., Dublin, $\mathrm{OH}$

12. National Electrostatics Corp., Middleton, WI (systems also)

Providers of ion technology systems include:

1. Varian Associates Electron Device Group, Palo Alto, CA

2. Physics International Co., San Leandro, CA

3. Applied Materials Inc., Santa Clara, CA

4. Colutron Research Corp., Boulder, CO

5. Graphite Die Mold Inc., Durham, CT

6. Eaton Corp. Semiconductor Equipment, Beverly, MA

7. Applied Science \& Technology Inc., Woburn, MA 
8. Wavemat Inc., Plymouth, MI

9. Potentials Inc., Austin, TX

10. Commonwealth Scientific Corp., Alexandria, VA

\section{IBAD Process Conclusion}

The IBAD process creates a coating up to ten micrometers thick. Tests have confirmed that the IBAD process for applying coatings is sound and acceptable. Additional proof of coating characteristics and qualities is typically required by users (see Lubricious Coatings section). The IBAD process including all its variations is known and available technology. New hardware for the process is currently being developed, for example use of radio frequency (microwaves) to generate plasma for the application of reactive coatings, with potential for technology protection. However, a new device would have to be invented for any kind of technology protection, not a new configuration of existing technology. The ANL IBAD process offers no potential for technolcgy protection. A coating process, the combination of technique and coating, is generally capable of obtaining technology protection. 


\section{Lubricious Coatings}

A literature search was conducted to identify prior and current efforts in developing lubricious coatings. According to ANL researchers and others, friction is a function of a system's property, not the just materials. Therefore, any commercialization plan would have to address the system parameters such as temperature, humidity, load, speed, and distance. Lubricious coatings are typically evaluated at various system parameters for wear rate, coefficient of friction, adhesion, and hardness. Since the ANL technology is silver coating on ceramic and boric acid coating on steel, we focused our search on these coatings and substrates. Keywords used in this search were lubricious coatings, solid lubricants, thin film coatings, ion assisied coatings, and silver, diamond, and boron coatings. On-line sources were:

- Compendex Plus;

- Ceramic Abstracts;

- Fluidex; and

- NTIS.

ITI reviewed the information and selected to report findings that are relevant to the ANL work. The findings are organized by coating and substrate with details of wear rate, coefficient of friction, and system parameters included if they were readily available.

\section{Coatings and Substrates}

- ANL coating researchers have actively presented their findings at conferences and in journal articles over the past two years. The following paragraphs summarize the ANL silver coatings in terms of IBAD technique, substrate, and coating characteristics.

The technique for applying the silver coatings on ceramics includes dual evaporators, a hot cathode Kaufman like ion gun for argon and oxygen ions at an energy level of $1000 \mathrm{eV}$, room temperature, vacuum pressure of 10 to the minus $5 \mathrm{~Pa}$, and ion sputter cleaning by oxygen or argon and oxygen.

Ceramic substrates are alumina/sapphire, silicon nitride and zirconia.

The silver coatings were evaluated by pin-on-disk and oscillating slide tests; no products have been tested. System parameters were room temperature to 
400 degrees centigrade, loads of $5-10 \mathrm{~N}$ or mean Hertzian pressure of $.8 \mathrm{GPa}$, sliding distances of up to 2 kilometers, velocities of .05-1 meters per second, and humidities of $16-20 \%$. Under these conditions the silver coatings on ceramic demonstrated elimination or significantly reduced wear rate (in some cases by a factor of 3000 ), significantly reduced coefficient of friction, and adhesion strengths higher than $70 \mathrm{MPa}$.

- Calcium floride/silver coating on ceramic (silicon nitride) has been researched by Bhattacharya of Universal Energy Systems in Dayton for Wright-Patterson AFB. Application technique is IBAD. In general, the researchers concluded that the $I B A D$ technique for fabricating self lubricating surfaces appears to have good technical feasibility for defense and industrial applications. They mention the overall simplicity and scalability of the technique as primary advantages. Likely applications include engine seals and bearings and components of gas turbine engines.

Evaluation of this coating shows it to be very adherent and have significantly low friction and wear characteristics at room and elevated ( 800 degrees C) temperatures. Since no product was specifically mentioned in the evaluation of this coating, we believe this is a test lab evaluation. Two other coatings were studied, titanium dioxide and cadmium oxide, which probably used reactive sputtering or $\mathrm{IBAD}$ techniques.

- A chromium carbide based composite combined with silver (a low temperature lubricant) and barium fluoride/calcium fluoride eutectic (a high temperature lubricant) solia' lubricant coating was researched by Dellacorte, a doctoral student, while at NASA's Lewis Research Center in Cleveland. This composite coating provides good wear resistance and low friction for sliding contacts from room temperature to over 900 degrees centigrade in reducing or oxidative environments. Test application was a braided ceramic slide seal against a variety of metal surfaces for hypersonic flight vehicles.

- Gates and Hsu obtained in 1980 a U.S. patent for aluminum hydroxides as a solid lubricants believed to on an alumina ceramic substrate.

- Diamond coatings on metal (germanium) were iscussed at a conference on military microwaves held in Europe in 1984. Characteristics of the diamond film valued for a military infrared application include excellent transmission over a wide waveband (thermal range of 8 to 11.5 microinches), a hard and protective film, low absorption, and ability to bond well with germanium. It is now a military standard for a coating on exposed germanium.

In addition, Cak Ridge National Laburatory also stems to be doing research in diamond films. In 1989, Blau (an Oak Ridye researcher) presented a paper 
on filament grown diamond films, visited a Swiss firm (CSEM) that provides coating services for the European space effort, and toured two tribology labs which are internationally recognized state of the art equipment and research.

- Boric acid coatings on steel are being researched by ANL researchers. These coatings can withstand temperatures up to 100 degrees centigrade and humidity up to $50 \%$.

- In 1889, Krachun, Krachun and Morar published in the Soviet Journal of Friction and Wear successful results of studies of antiwear and antiscuffing properties of boric acid-like solid lubricants on substrates that are the products of interaction with caprolactam of heteropoly acids containing tungsten, vanadium, phosphorus, and molybdenum. These materials form acids corresponding to boric acid. It is unclear from the abstract whether this lubricant is bonded to the substrate.

- Lead films on steel valued for their lubricating capabilities were studied in high vacuum at temperatures between 20 and 300 degrees centigrade. Coatings wcre sputtered and electroplated. Single lead coatings; double layers of lead and $\mathrm{Mo}, \mathrm{Ta}, \mathrm{W}, \mathrm{Ag}$, and $\mathrm{Cu}$; and blended layers of lead and silver, copper, platinum or molybdenum were studied. Lead coatings are typically appropriate for low temperature applications.

- Copper-nickel coating on stainless steel by IBAD results in good adhesion and a decrease in the pin-on-disk friction coefficient by the Ecole des Mines in France (1988).

- A compound coating on a bearing assumed to be metal consists of $\mathrm{Cu}$-Sn-PMoS sub 2 includes a thin layer of $P$ compourici around the MoS sub 2 particle. (Source: Kohno, 1989, Funtai Oyobi Funmatsuyakin, 36[4]).

- Hot pressed aluminum nitride acts as a solid lubricant on an unknown substrate under mild sliding conditions. (Source: Iwaso and Murao, Yogya Kyokaishi, 84[1]). 


\section{Procedure to Acquire Technology Protection for Coatings}

Barriers to commercialization of coating systems, according to Spire, include a long and expensive evaluation process due to:

1. waiting and budgeting test time (c.g., obtaining engine test time);

2. end user may be confronted by changing specifications; and

3. failure of adjacent parts not related to ion technology.

\section{Lubricious Coating Conclusion}

Marketing research continued for the silver coating because our review identified only three other silver coatings for ceramics.

Marketing research was concluded for the boric acid coating because the low temperature requirement limited the market potential. Further, lubricious coatings currently exist for metals.

\section{Investigation of Commercial Potential for Silver Coating on Ceramic}

The purpose of our investigation was to identify commercial applications and unmet needs for a lubricious coating for ceramic. Telephone interviews were conducted with three ion technology providers and several ceramic manufacturers.

The ion technology firms contacted include a leading service and equipment manufacturing firm, a service provider, and an equipment manufacturing firm. Commercial IBAD will most likely involve people from these three segments of the industry. These firms are staffed by people with advanced academic degrees and they tend to conduct in-house research or license university innovations. Of the three firms contacted, two already offer IBAD services to their client?. One of them had the technical capability for five years and began offering IBAD service with silver, gold, diamond, and boron nitride coatings to their clients mid 1990. Two of the firms referenced Argonne National Laboratory as an IBAD research center; however, one felt that Argonne had "nothing different to offer his firm that it had not already researched."

All three interviewees strongly felt the surface engineering, including ion coating and 
modification, was an expanding market. When asked to estimate market size, all said the potential market is huge and untapped. They cited the billions of dollars lost due to part replacement and wear. Respondents said that the market is highly "nichified." Coatings are sold on an application basis and there are numerous ccatings available.

All the firms evaded questions tilat asked them to characterize the end user market or the applications. They cited proprietary work as the reason for not discussing markets and applications.

To investigate applications, we contacted several ceramic manufacturers. We focused on ball bearing manufacturers and manufacturers of industrial ceramic components. Overall support from ceramic firms for a lubricious coating on ceramic was weak. The market need does not currently exist, is small and experimental, or is not yet recognized. A promising application is hybrid bearings for machine tools, turbine/refractory engines, and high vacuum specialty pumps.

Hybrid bearings consist of ceramic balls with rolling and sliding friction on a steel track. Machine tool builders need to make the tools go faster to make parts faster. Hybrid bearings achieve this goal. There is potential that a coating on the ceramic ball could increase speeds even further. Conditions under which a coating on ceramic machine tool application must perform include 1.2-1.8 million $\mathrm{dn}$ ( $\mathrm{dn}$ equals bore size of bearing in millimeter times shaft r.p.m), compression stresses of 200,000-400,000 p.s.i., and longevity of 3-5 years.

High vacuum specialty pumps need bearings to operate at pressures where conventional lubricants do not work. In addition, ceramic pump seals need a lubricious coating.

Turbine/refractory engine applications, for example, roller cams, are a commercial potential for a a lubricious coating on ceramic. However, these engines are in an experimental, developmental stage for brittleness reasons. Estimates of ceramic engines for commercial application, based on FAA approval procedures, range from five to ten years.

The existing market for hybrid bearings is small and in its infancy. 
Concerns about coatings mentioned by end users were:

- capability to coat large parts;

- high application reliability, especially in automotive;

- longevity;

- tight tolerances capability; and

- cost.

Discussions with people in one ceramic ball bearing manufacturer highly polishes the ceramic surface to reduce friction and said clients have not requested additional coating or increased lubri ${ }^{\circ} y$. Another manufacturer of advancec' ceramics said no current need for ceramic coating; however, the firm had pilot producticn of diamond coatings on ceramic. A bearing application engineer for the aerospace industry mentioned no current need, but suggested we speak with turbine engine manufacturers.

\section{Commercial Potential Conclusion}

A future market may exist for a lubricious coating on ceramic, but its development and growth is dependent on the ceramic industry which is still in its infancy and has been for some time. Any substantial market that does precipitate will be serviced by existing ion technology providers. Therefore, we recommend that market research conclude for the ANL silver coating on ceramic IBAD process. 


\section{Bibliography}

Alexander, R.B., "Nitrogen Ion Implantation: Barriers to Industrial Acceptance and Prospects for the Future." Carbide and Tool Journal v 21 n 3 May-June 1989, p 21-24.

Bhattacharya, R.S., "Self-Lubricating Surfaces by Ion Beam Processing." Universal Energy Systems Inc., Dayton, OH, 1989 August- 1990 March.

Blau, P.J. "Tour of Swiss Facility for Chemical Vapor Deposition." Foreign Trip Report, September 1988, Oak Ridge National Lab, TN.

Corbett, R.T., B.C. Monachan, "Diamond Coatings for I R Components." Conference Proceedings: Military Microwaves 1984, Microwave Exhibitions \& Publ Ltd., Tunbridge Wells, England, p 121-125.

Dellacorte, C., "Experimental Evaluation and Application of High Temperature Solid Lubricants." (Final Doctoral Thesis) National Aeronautics and Space Administration, Cleveland, OH, Lewis Research Center, Jan 1980.

Erdemir, A., G.R. Fenske, F.A. Nichols, R.A. Erck, "Solid Lubrication of Cerarnic Sufaces by IAD-Silver Coatings for Heat Engine Applications." Presented at the 35th STLE/ASME Tribology Conference in Fort Lauderdale, FL October 1989.

Erdemir, A., "Tribological Properties of Boric Acid and Boric-Acid-Forming Surfaces: Part I Crystal Chemistry and Mechanism of Self-Lubricating of Boric Acid" and "Part II Mechanisms of Formation of Self-Lubricating of Boric Acid Flims on Boron- and Boric Oxide-Containing Surfaces." Presented at the 45th Annual STLE Meeting May 1890 in Denver, CO.

Erdemir, A., D.E. Busch, R.A. Erck, G.R. Fenske, R. Lee, "Ion-Beam-Assisted Deposition of Silver Films on Zirconia Ceramics for Improved Tribological Behavior." Presented at ASME/STLE Conference October 1990.

Erck, R.A., and G.R. Fenske, "Adhesion of Silver Films to Ion-Bombarded Alumina." Materials Research Society Symposium Proceedings, vol 157, 1990, p 85-90.

Fenske, G.R., A. Ardemir, R.A. Erck, C.C. Cheng, D.E. Busch, R.H. Lee, F.A. Nichols, "Ion-Assisted Deposition of High-Temperature Lubricious Surfaces." Presented at - 35th STLE/ASME Triboligy Conference, October 1989.

Gates, Richard S., Stephen M. Hsu, Aluminum Hydroxides as Solid Lubricants, US Patent No. US 4918829, 24 April 1890.

Gerkema, Jan, "Lead Thin Film Lubrication." Wear, v 102 n 3, April 1 1985, p 241-252. 
Krachum., S.V., A.T. Krachum, V.E., Morar, "Study of New Solid Lubricants." Soviet Journal of Friction and Wear, v 10 n 3 1888, p 80-84.

Von Stebut, J., K. Anoun, J.P. Riviere, R.J. Gaboriaud, "Modification of Surface Mechanical Properties of $\mathrm{BBAD}-\mathrm{Cu} \mathrm{Ni}$ Coatings." 16th International Conference on Metallurgical Coatings, April i 7-21, 1989. 


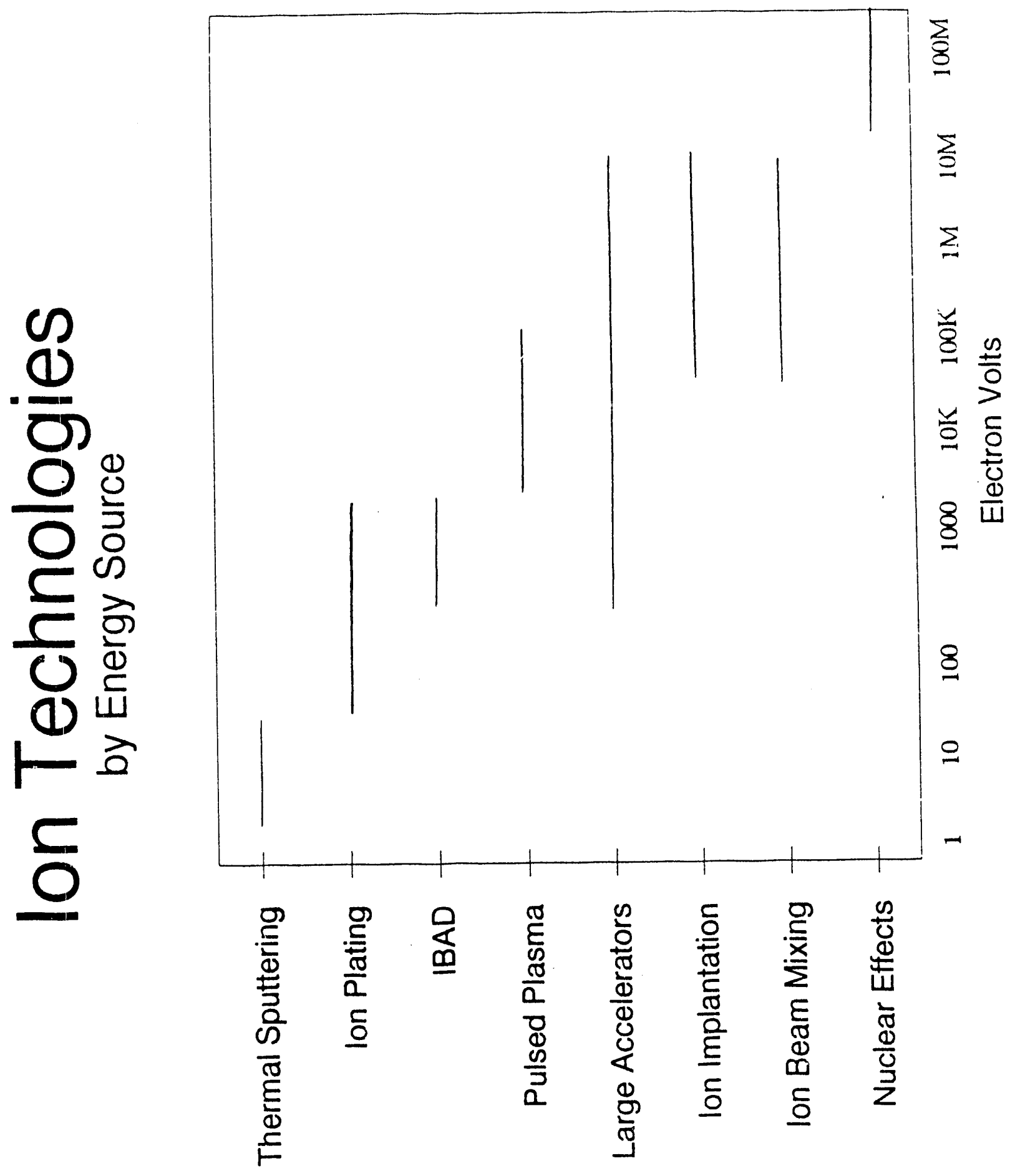



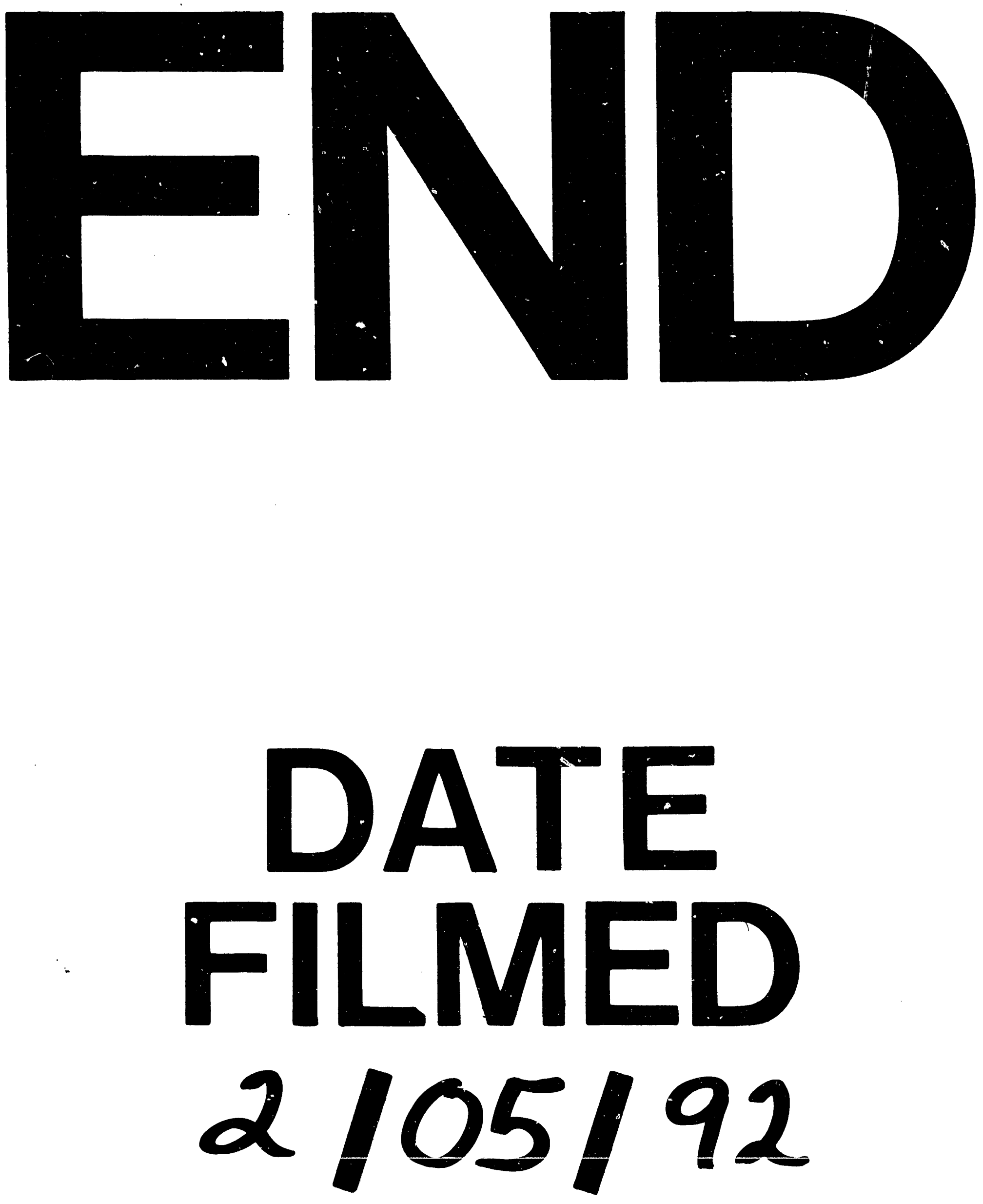

I 


$$
-
$$

